\title{
Development of a model for auto-ignition delays and its use for the prediction of premix combustion reliability
}

\author{
Roda Bounaceur, Pierre-Alexandre Glaude, Baptiste Sirjean, René Fournet, \\ Laboratoire Réactions et Génie des Procédés (LRGP) CNRS, Université de Lorraine \\ 1, rue Grandville - BP 20451 - 54001 Nancy, France \\ Pierre Montagne, Matthieu Vierling, \\ GE Energy Product-Europe, \\ 20 avenue de Maréchal Juin, BP 379, 90007 Belfort, France \\ Michel Molière \\ IRTES-LERMPS - Université de Technologie de Belfort Montbéliard \\ 90010 Belfort Cedex, France
}

\begin{abstract}
Except in diesel engine applications, auto-ignition is an unwanted event from a general safety and reliability standpoint. It is especially undesirable in the premixing process involved in most low NOx combustion technologies. Therefore, in addition to auto-ignition temperature, autoignition delay (AID) is a key data for the design of modern combustors including gas turbine ones. The authors have investigated the detailed kinetic mechanisms leading to autoignition and established practical AID correlations involving the fuel composition, its temperature, pressure and equivalence ratio. The correlations brought about during this program offer a good reconciliation between calculated and experimental AID through a wide range of fuel composition, initial temperature and pressure. Validations were mainly done against data acquired with experimental setups consisting in shock tubes and rapid compression machines. The auto-ignition delay times of methane, pure light alkanes and various blends representative of several natural gas and process-derived fuels have been reviewed. For each fuel mixture, this study procures a simple equation linking the auto-ignition delay time to the temperature, pressure and equivalence ratio. As a direct application of this work, the authors have evaluated the risk of auto ignition in the premixing zone of a combustor characterized by a residence time and an associated probability density function. The results of this simulation stress the key role of larger hydrocarbon in the risk of flash-back events.
\end{abstract}

\section{INTRODUCTION}

Auto-ignition is a complex, highly non-linear phenomenon that has been the matter of extensive experimental and theoretical research for decades, but still strongly resists attempts of modeling through combustion kinetics and fluid dynamics. Nonetheless, auto-ignition data represent crucial inputs in process safety and combustion reliability and are often sorely lacking when the fuel composition and the pressure depart from usual values. Therefore, the prediction of auto-ignition in terms of both AIT (auto-ignition temperature) and AID (auto-ignition delay) over extended pressure and fuel composition ranges would represent a great step forward for the engineering community.

In a previous paper [1] the LRGP laboratory and GE Power have set out a method that aimed at evaluating the AutoIgnition Temperature of a series of industrial gas fuels and was successfully validated against a number of experimental results compiled from the abundant literature found in this field. Using the same methodology the present paper addresses the prediction of AID and continues this overall effort to improve the knowledge of auto-ignition phenomena. The first part of this paper will set out the modeling of autoignition delay times based on the same methodology as the one developed in the previous paper, using detailed kinetic modeling. For different gas and blend of interest, auto-ignition delay times are calculated for temperatures ranging from 600 to $1500 \mathrm{~K}$, pressures from 1 to 25 bar and with equivalence ratio ranging from 0.2 to 4.0 .

A second part will be devoted to stress the relevance of AID in modern combustion systems taking as example the occurrence of "spontaneous ignition" in premix combustion, a risk that materializes when the residence time of the fuel in the premixing zone exceeds the local auto-ignition delay, which depends on the fuel composition, equivalence ratio, pressure and temperature. 


\section{KINETIC MODELING}

Several comprehensive kinetic models for the oxidation and combustion of natural gas and light hydrocarbons have been published in the literature in the last years. The University of Leeds modeled successfully the combustion of methane at typical flame temperatures [2]. Another popular detailed mechanism is GRI-mech 3.0 [3], which was optimized for the combustion of methane at high temperature.

Mixtures of light hydrocarbons representative of natural gas can be modeled by GDF-Kin [4] and Konnov's models [5], which have been regularly updated, and contain also the reactions for the formation of nitrogen oxides. Models for the combustion of light alkanes have been developed at the Lawrence Livermore National Laboratory (LLNL) and include the formation of peroxy radicals that are responsible for the reactivity at low temperature [6]. AramcoMech 1.3 has been written hierarchically with systematic validations for each reactant over a wide range of pressure and equivalence ratio at National University of Ireland at Galway (NUIG) [7]. All these models have been validated against experimental ignition delay times, but at temperatures much higher than AIT. As shown previously [1], most of these mechanisms aim at the simulation of flames in burner or engine conditions and their validity is assumed only in high temperature conditions, i.e. above $1000 \mathrm{~K}$.

Some mechanisms, such as LLNL or AramcoMech 1.3, contain the low temperature alkyl radical species in order to account for the formation of peroxy radicals but they do not involve all the alkanes contained in natural gas fuels. Peroxy radicals are responsible for cool flames and the for NTC (Negative Temperature Coefficient) behavior that is specific of alkanes.

Auto-ignition, a key consideration in process safety, is characterized by much lower temperatures, slower reactions and much longer timescales than flames. Some specific reactions, like those of peroxy radicals, can be neglected at high temperature but become critical reaction paths at low temperature because they yield branching agents and fragile molecules, the fast decomposition of which dramatically promotes the global reactivity and finally the ignition.

The following scheme can be used to summarize the oxidation of hydrocarbons at low temperature:

Unsaturate

HO

A new model has been developed in our group for the prediction of AIT of gas mixtures [1]. It contains reaction bases for the lighter species, i.e. the $\mathrm{CO} / \mathrm{H}_{2}$ sub-mechanism, methane, and ethane [8], and uses the software EXGAS [9] for the low temperature chemistry of $\mathrm{C}_{3}-\mathrm{C}_{5}$ alkanes. This software has been patiently developed at the LRGP for years to enable the automatic generation of mechanisms for the gasphase oxidation of hydrocarbons. This mechanism contains
209 species involved in 1473 reactions; it can be obtained upon request.

The model has proven its ability to predict rather well AITs, which correspond at the lowest temperatures of reaction, with typical timescales amounting in minutes. In the present work, the model has been refined for the prediction of the ignition delay (AID) times of gas mixtures at low and high temperatures in order to account for the widest conditions encountered in industrial processes. Its validation has been made against experimental results from the abundant literature found on this subject. The corresponding simulations were performed using CHEMKIN II [10]: this software solves the mass and energy equations that are involved in the main laboratory reactors.

Figure 1 compares the results of such simulation performed for methane with some experimental auto-ignition delay times obtained in shock tube. The model reproduces very well the AIDs measured at moderate pressure and in stoichiometric conditions [11] (fig. 1a) as well as those measured at elevated pressures and in rich conditions [12] (fig. 1b). Simulation are within the range of reproducibility of the experiments and the apparent activation energy is well simulated. The capability of the model to deal with hydrogen and hydrogen/methane blends has be demonstrated previously [1]. Ethane and propane, two significant alkane components of natural gas, are known to increase its reactivity. Figure 2 displays the comparison between simulation and experimental results data for lean and rich mixtures [13]. Propane is the first of the alkane series that exhibits the specific low temperature behavior consisting in cool flame and NTC. The model can reproduce these properties: Figure 3a compares the AID simulation results with those obtained with a rapid compression machine [14]. Figure $\mathbf{3 b}$ moreover shows the suitability of the model for reproducing high temperature shock tube experiments [15]. Similar conclusions apply to nbutane (Figure 4a) and n-pentane (Figure 5) which exhibit still stronger NTC behaviors at low temperature: the experimental results come from experiments performed in Lille with a rapid compression machine [16,17]. The high temperature ignition of $n$-butane is correctly modeled in shock tube both at low and high pressure (Figure 4b) $[18,19]$. Note that discrepancies are larger in the case of simulations of Rapid Compression Machine results in the NTC region (Fig 4a, 5a). The complexity of the device, especially the nonuniform temperature and the gas motion, is not captured by the assumption of an adiabatic reacting core in the 0-D calculation. Eventually, the ability of the model to simulate mixtures or natural gas has also been checked, as displayed: Figure 6 shows that the model correctly simulates the results given by a high pressure shock tube experiments in the cases of: (i) a mixture of $70 \%$ methane $/ 30 \%$ propane/[20] and (ii) an Algerian natural gas [21]. 

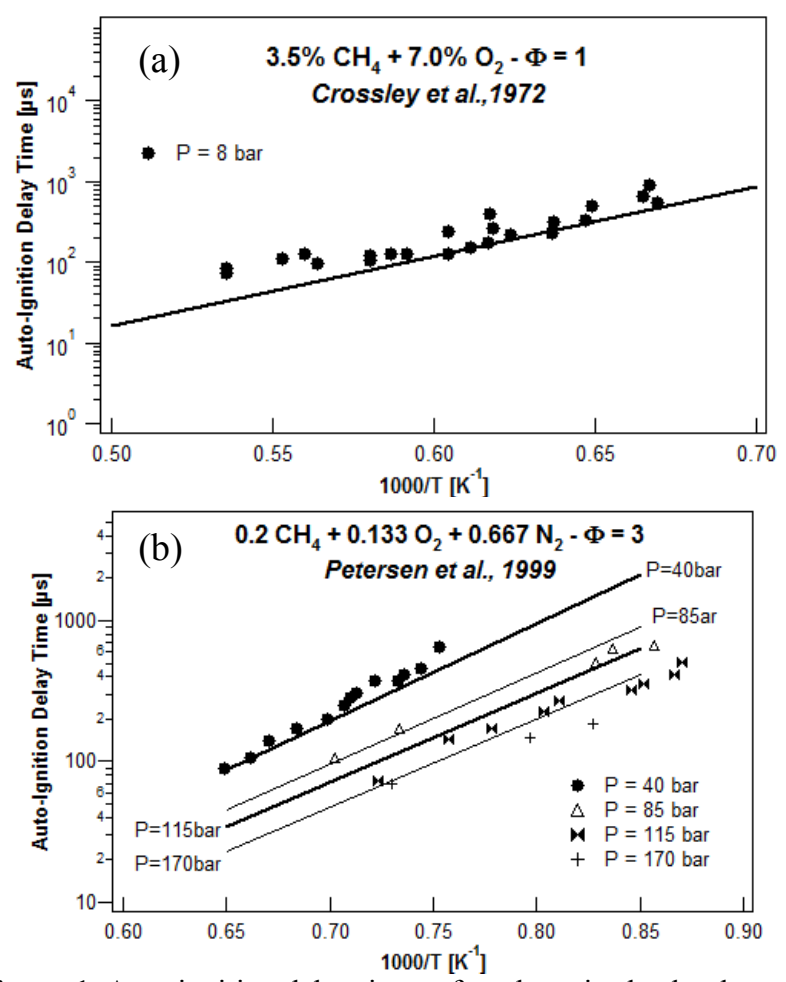

Figure 1: Auto-ignition delay times of methane in shock tube under high pressure. Points are experimental data, lines are simulations.
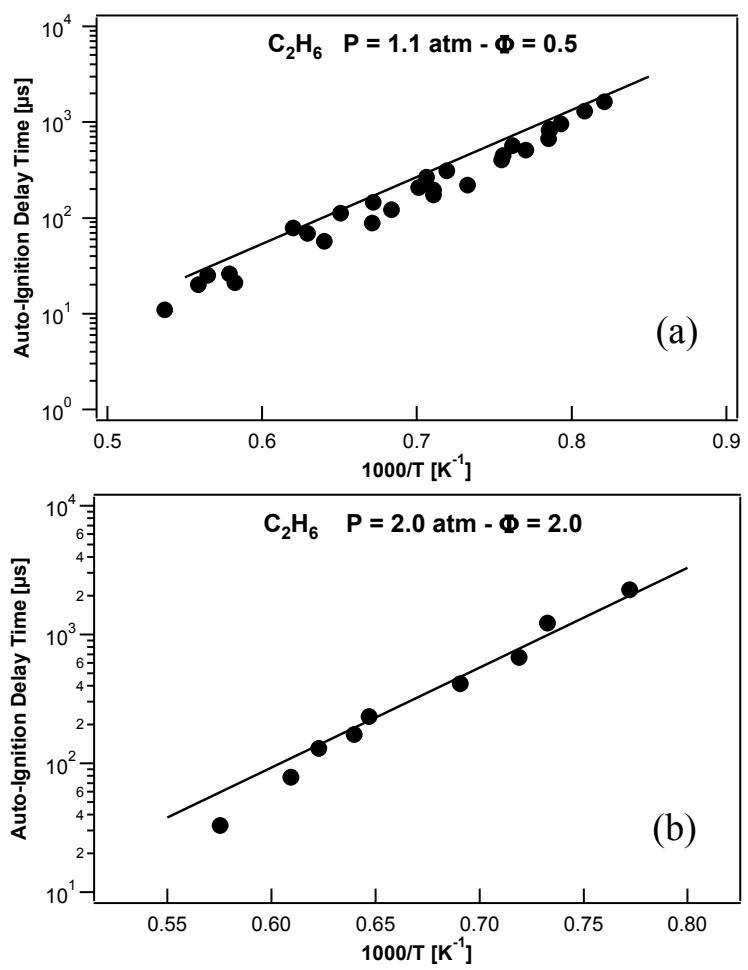

Figure 2: Auto-ignition delay times of ethane in shock tube for different equivalence ratios. Points are experimental data, lines are simulations.
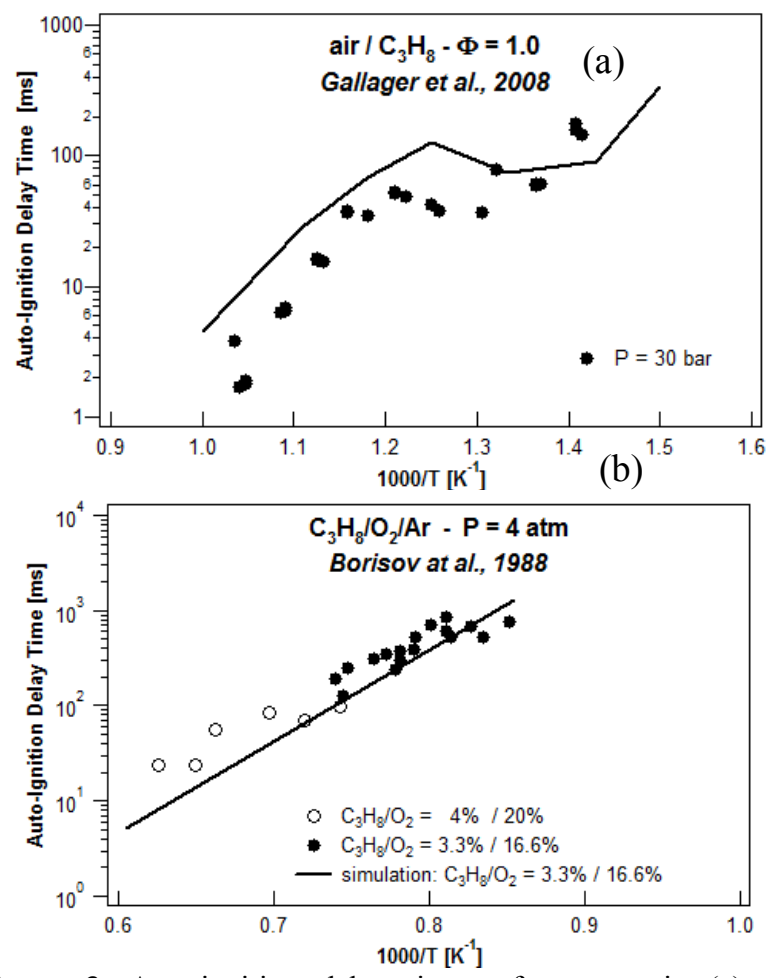

Figure 3: Auto-ignition delay times of propane in (a) rapid compression machine and (b) shock tube. Points are experimental data, lines are simulations.
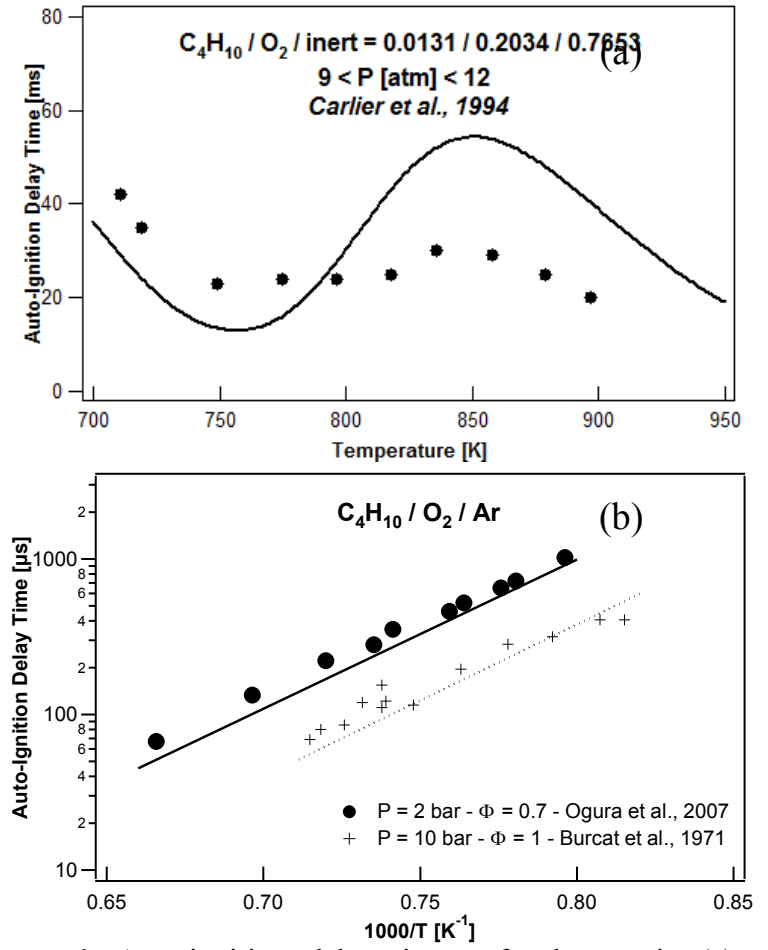

Figure 4: Auto-ignition delay times of $n$-butane in (a) rapid compression machine and (b) shock tube. Points are experimental data, lines are simulations. 


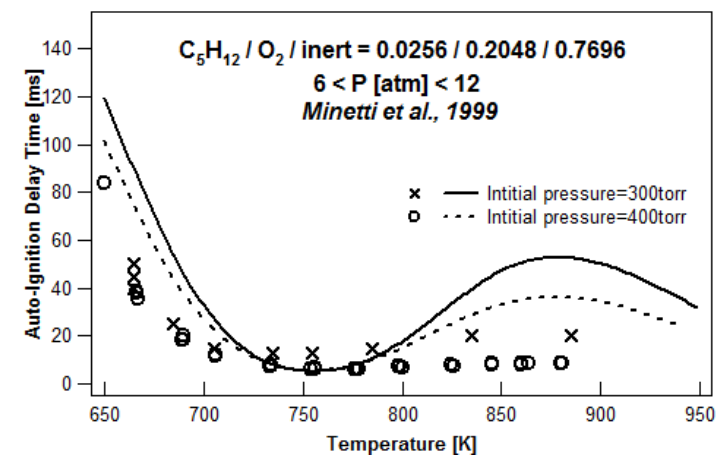

Figure 5: Auto-ignition delay times of n-pentane in rapid compression machine. Points are experimental data, lines are simulations.
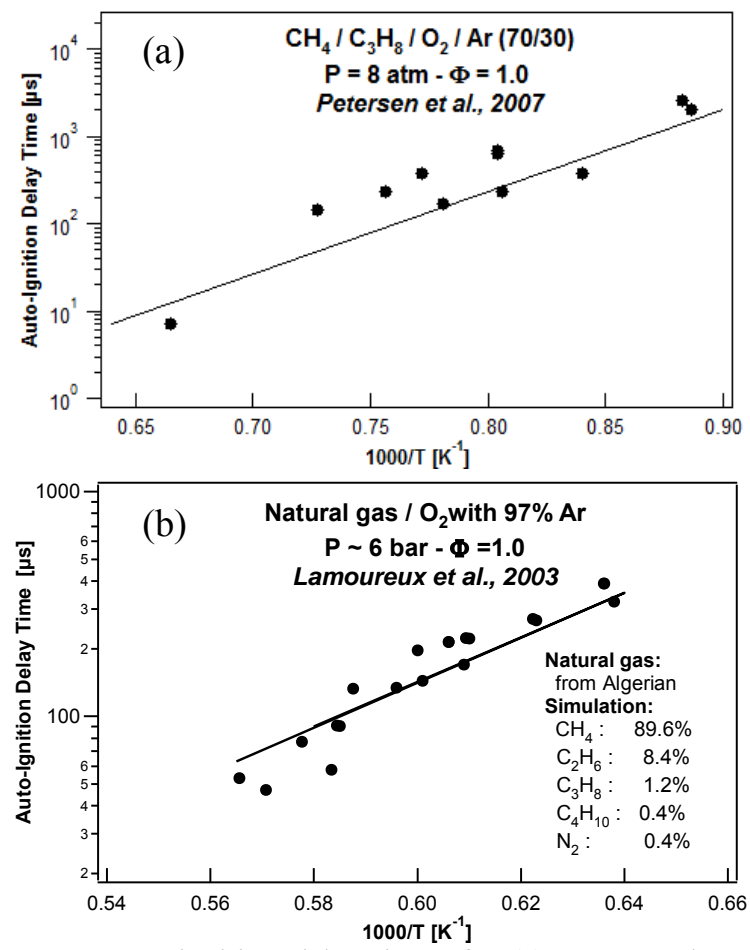

Figure 6: Auto-ignition delay times for (a), 70\% methane-30\% propane (b) natural gas in shock tube. Points are experimental data, lines are simulations.

Ignition delay times of alkanes vary according to the temperature, pressure and equivalence ratio of the mixture. Above $1000 \mathrm{~K}$, a linear variation according to the temperature is found using an Arrhenius plot but at lower temperature, a nonlinear behavior is observed. Additions of $\mathrm{C}_{2+}$ alkanes to methane decrease the ignition delay times but the intensity of this "promoting effect" significantly depends on temperature and pressure. In this respect we have performed numerous comparisons between experimental data and the results of simulations using the present model; these comparisons involve large ranges of mixtures, equivalence ratios, pressures and temperatures.

The outcome of this comparison work is that the AID values and the variation trends agree well, even at low temperature, where experimental uncertainty are the highest and the chemical mechanisms the most complicated.

\section{PREDICTIVE CALCULATIONS FOR PROCESS GASES}

The model being validated, we have used it to predict the AIDs of several gas fuels of interest in gas turbine applications, in order to assess auto-ignition risks, in function of pressure and equivalence ratio. Table 1 shows the compositions of the selected gas mixtures. Mixture B1 is methane, taken as a reference. Mixtures B2 and B3 that contain propane and butane respectively, are representative of natural gas fuels. B4 represents a classical natural gas burned in gas turbines while B5 stands for methane enriched in hydrogen. B6 is a typical Coke Oven Gas; B7 a low BTU Blast Furnace Gas, and B8 a typical blend of the B6 and B7. For all blends, the equivalence ratio ranged from 0.2 to 4.0 and pressure from 1 to 25 bar. The simulations assumed a closed vessel without thermal transfer. For instance, figure 7 illustrates the results obtained with the natural gas B4. In the high temperature range, above $1000 \mathrm{~K}$, one observes a linear Arrhenius behavior, whereas the curve exhibits a deviation at low temperature, due to the specific behaviors developed by the $\mathrm{C}_{3}$ to $\mathrm{C}_{5}$ components. This effect is more important with very rich mixtures (e.g. with an equivalence ratio of 3.7) and at lower pressure (results not shown in figure 7).

Table 1: Composition of the fuels studied ( $\%$ mol.)

\begin{tabular}{|c|c|c|c|c|c|c|c|c|}
\hline & $B 1$ & B2 & B3 & B4 & B5 & $B 6$ & $B 7$ & B8 \\
\hline $\mathrm{CO}$ & & & & & & 7.0 & 25.0 & 19.0 \\
\hline $\mathrm{CO}_{2}$ & & & & 0.81 & & 3.0 & 17.0 & 12.3 \\
\hline $\mathrm{H}_{2}$ & & & & & 25.0 & 60.0 & 2.0 & 21.3 \\
\hline $\mathrm{N}_{2}$ & & & & 1.94 & & 6.0 & 55.0 & 38.7 \\
\hline $\mathrm{O}_{2}$ & & & & & & 1.0 & 1.0 & 1.0 \\
\hline $\mathrm{CH}_{4}$ & 100 & 93.0 & 95.0 & 89.15 & 75.0 & 21.0 & & 7.0 \\
\hline $\mathrm{C}_{2} \mathrm{H}_{6}$ & & & & 6.09 & & 2.0 & & 0.7 \\
\hline $\mathrm{C}_{3} \mathrm{H}_{8}$ & & 7.0 & & 1.50 & & & & \\
\hline $\mathrm{C}_{4} \mathrm{H}_{10}$ & & & 5.0 & 0.40 & & & & \\
\hline $\mathrm{C}_{5} \mathrm{H}_{12}$ & & & & 0.07 & & & & \\
\hline
\end{tabular}

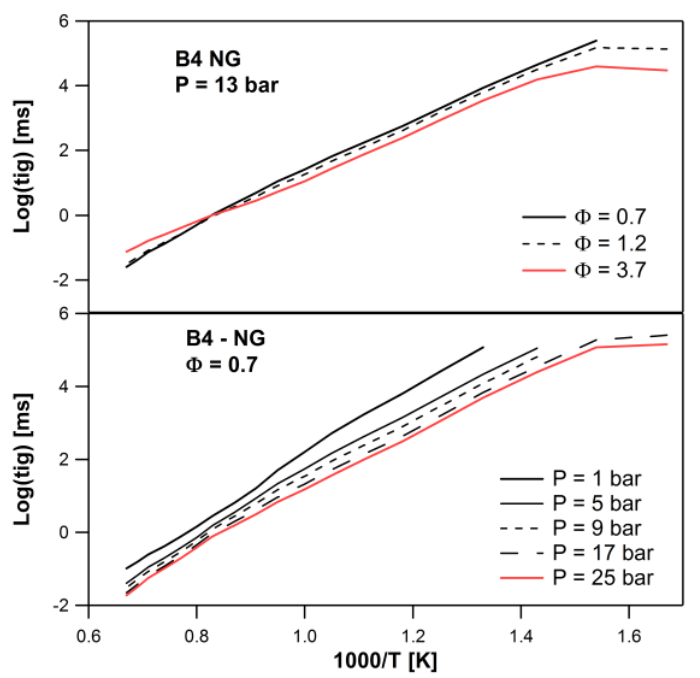

Figure 7: AID simulations for the blend B5 in function of pressure and equivalence ratio: B5 is representative of a natural gas. 
Using the present model, we have evaluated the AID at different initial temperatures, pressures, and equivalence ratios, for the 8 blends listed in table 1 . Then we have used these results as samples to build up a generic correlation based on an Arrhenius-like equation which is a widely used form in auto-ignition studies:

$$
A I D \propto \varphi^{x} P^{y} \exp \left(\frac{E}{R T}\right)
$$

While AIDs monotonically decrease with the initial temperature for a given equivalence ratio (Figure 7), the apparent activation energy is found lower at high temperature than at low temperature. Furthermore, AIDs vary nonmonotonically with the equivalence ratio for a given initial temperature. Therefore, a single set of parameters cannot represent the entire range of possible conditions. Therefore, for the purpose of process safety studies linked to gas turbine (GT) operation, we defined "reduced" parameters ranges: temperature between 600 and $900 \mathrm{~K}$; pressure between 1 and 25 bar; equivalence ratio between 0.2 and 4.0. Then we tested the adequacy of the generic correlation (1) with the blend B4. On this range, correlation coefficients are above 0.999 except 0.992 and 0.986 for fuels B2 and B3, respectively. Figure 8 compares the AIDs calculated with the full kinetic mechanism to those obtained with the fitted correlation: the correlation proves effective on the reduced temperature range. Although the agreement deteriorates at low pressure and high equivalence ratio because of the enhancement of the NTC behavior of the $\mathrm{C}_{2+}$ alkanes, combustion in gas turbines is not ultra-rich $(\varphi>2)$ but lean and occurs at elevated pressure; moreover $\mathrm{C}_{2+}$ species remain minor components in many blends of interest. Consequently, practical correlations for the evaluation of the order of magnitude of AIDs can be derived and enable a fast and easy estimation as compared with a detailed modeling, which should be preferred, however, for a deeper investigation or for better accuracy.

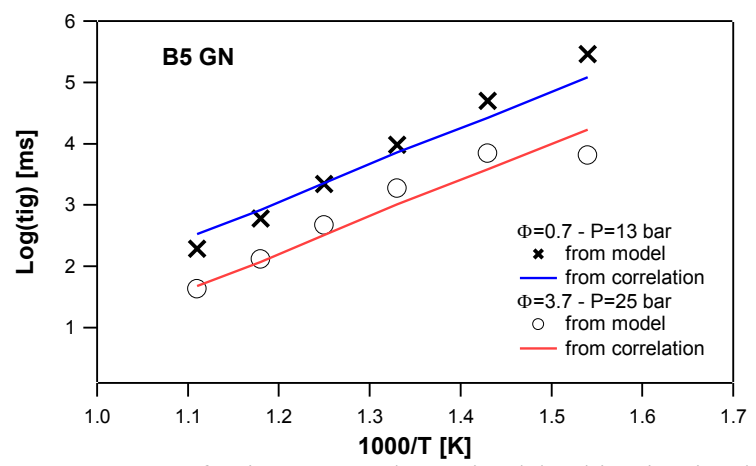

Figure 8: AID of mixture B4 determined by kinetic simulations (dots) and correlation (lines) as a function of the temperature.

The following correlation expresses the AID as a function of the operating parameters for the different blends:

$\log _{10} \mathrm{AID}=k_{0}+k_{1} \times \frac{1000}{T}+k_{2} \times \log _{10} P+k_{3} \times \log _{10} \varphi(2)$

AID represents the auto-ignition delay [ms], $\mathrm{P}$ the pressure [bar], $\mathrm{T}$ the temperature $[\mathrm{K}]$ and $\varphi$ the equivalence ratio. Table 2 summarizes the coefficients computed for the different blends. These expressions are valid for pressures from 1 to $25 \mathrm{~atm}$, equivalence ratios from 0.2 to 4 and temperatures from 600 to $900 \mathrm{~K}$.

Table 2: Coefficients ki contained in correlation (2) for the 8 blends considered.

\begin{tabular}{ccccccccc}
\hline & $\boldsymbol{B 1}$ & $\boldsymbol{B 2}$ & $\boldsymbol{B 3}$ & $\boldsymbol{B 4}$ & $\boldsymbol{B 5}$ & $\boldsymbol{B 6}$ & $\boldsymbol{B 7}$ & $\boldsymbol{B} \boldsymbol{8}$ \\
\hline $\mathrm{k}_{0}$ & -5.87 & -1.35 & -0.20 & -3.16 & -7.62 & -7.41 & -7.31 & -7.41 \\
$\mathrm{k}_{1}$ & 8.26 & 4.44 & 3.10 & 5.96 & 9.49 & 9.26 & 9.51 & 9.35 \\
$\mathrm{k}_{2}$ & -0.83 & -1.08 & -1.16 & -0.98 & -0.59 & -0.67 & -0.14 & -0.58 \\
$\mathrm{k}_{3}$ & -0.58 & -0.87 & -1.21 & -0.72 & -0.51 & -0.48 & -0.57 & -0.47 \\
\hline
\end{tabular}

In conclusion the generic correlation (2) represents an interesting tool for a fast evaluation of the auto-ignition delays of industrial gas fuels used in variable temperature, pressure and fuel/air ratio conditions.

\section{IMPORTANCE OF AID IN PREMIX COMBUSTION}

Premix combustion is a good example of the relevance of auto-ignition delay in industrial processes. Indeed autoignition sets a feasibility barrier that imposes on combustion engineers in lean premix combustion. The principle of lean premix combustion is to get fuel and air thoroughly mixed inside a premixing zone (PrZ) located upstream of the actual combustion zone $(\mathrm{CbZ})$. Because the emission of NOx is virtually an exponential function of the temperature which itself increases with the equivalence ratio, one needs to obtain an air/fuel mixture as homogenous as possible since any richer spot would generate a locally high NOx contribution that might defeat the low NOx objective. In this regard, figure 9 [22] shows the effect of "unmixedness" (expressed as the standard deviation $S$ of the equivalence ratio $\varphi$ calculated throughout the PrZ, $S=\left[\Sigma\left(\varphi_{\mathrm{i}}-\varphi_{\text {mean }}\right)^{2} / \mathrm{N}\right]^{1 / 2}$ where i represents a point of the premix zone and $\mathrm{N}$ the number of points) on the overall NOx emission: the combustor is fed with a generic $\mathrm{CH}_{4} /$ air premixing device operating at $\mathrm{P}_{\mathrm{PrZ}}=16$ bar, $\mathrm{T}_{\mathrm{PrZ}}=$ $650 \mathrm{~K}\left(377^{\circ} \mathrm{C}\right)$.

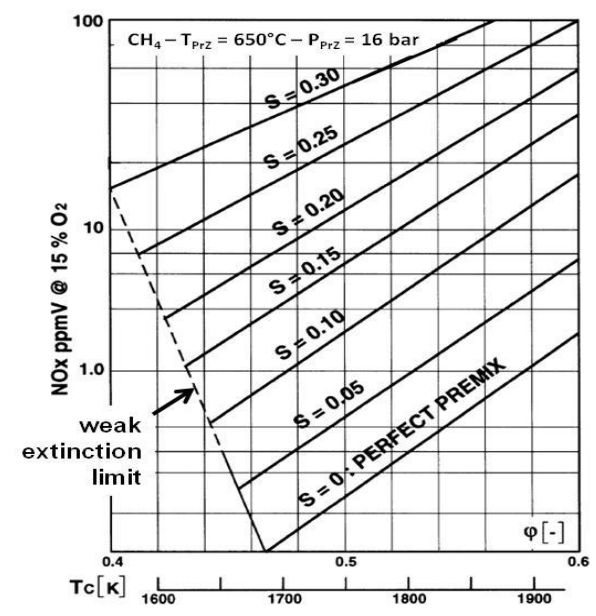

Figure 9: NOx emission in function of $\varphi$ and its standard deviation inside the premix zone

Now the degree of premixedness at the outlet of the PrZ directly depends from: (i) the turbulence intensity of the 
overall fuel/air flow during mixing and (ii) the residence time of the fuel molecules in this zone. However since the premix is performed above the AIT in modern engines, this residence time must be designed to be substantially lower than the AID associated with the specific fuel considered and the values of $\mathrm{T}_{\mathrm{PrZ}}$ and $\mathrm{P}_{\mathrm{PrZ}}$. Otherwise an unwanted "spontaneous ignition" ("SI") would occur in the PrZ and the flame would go backward from the $\mathrm{CbZ}$ into the $\mathrm{PrZ}$ which, as a result, is equivalent to a "flashback", the latter term being normally reserved for cases where the flame retro-propagates in the absence any upstream auto-ignition.

This point can be accounted for through a simple lagrangian approach in which one molecule of fuel is tracked during its transit through the PrZ and one compares its residence time to the AID value. If $Q$ represents the volume flow of the fuel/air mixture and V the volume of the PrZ, the mean value of " $t$ ", i.e. the average residence time " $\mathrm{t}_{\mathrm{m}}$ " equals $\mathrm{V} / \mathrm{Q}$. However, the residence time ( $\mathrm{t}$ ) of any group of molecules crossing the volume "V" of the PrZ is a random variable that typically obeys a log-normal law, assuming the distribution is monomodal. A log-normal process is typically used for a phenomenon which results from many independent random variables. Figure 10 shows the corresponding probability density function $\operatorname{Pdf}(\mathrm{t})$ and the cumulated distribution function $\operatorname{Cdf}(\mathrm{t})$ which is the Pdf's integral that tends towards 1 when $\mathrm{t}$ becomes infinite.

$$
\begin{gathered}
\operatorname{Pdf}(\mathrm{t})=\frac{1}{\mathrm{t} \sigma_{\log } \sqrt{2 \pi}} \exp \left[\frac{-\left(\ln (\mathrm{t})-\mathrm{t}_{m, \log }\right)^{2}}{2 \sigma_{\log }}\right] \\
\operatorname{Cdf}(\mathrm{t})=\frac{1}{2} \operatorname{erf}\left[\frac{\ln (\mathrm{t})-\mathrm{t}_{m, l o g}}{\sqrt{2} \sigma_{\log }}\right]
\end{gathered}
$$

where "erf" stands for the error function.

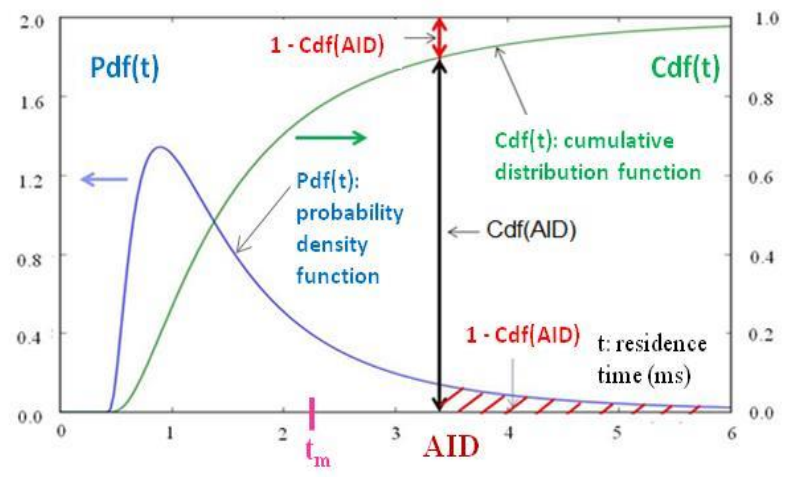

Figure 10: Probability density function $\operatorname{Pdf}(\mathrm{t})$ and cumulated distribution function $\operatorname{Cdf}(\mathrm{t})$ of the residence time $t$ (for the sake of legibility, AID has been taken exaggeratedly close to $t_{m}$ )

The meanings of the distribution parameters present in these definitions are given in Appendix 1. By definition, Cdf(AID), as shown in figure 10, represents the probability of a group of molecules residing less than AID seconds in the PrZ. Consequently [1-Cdf(AID)] represents the probability of an SI occurring, due to auto-ignition, while this group of molecules crosses the PrZ, which is the probability of a "one shot" SI. As shown in Appendix 1, the condition for having - for instance - less than one SI occurring during a reference operation period of $\mathrm{H}$ hours, can be with the following inequality involving a quadratic equation in $\mathrm{S}$ :

$$
0.5 S^{2}-1.41 \text { L.S }+\ln \left(\frac{A I D}{t m}\right)>0
$$

where:

- $\mathrm{S}$ is defined as: $\mathrm{S}=\left\{\ln \left[1+\left(\sigma / t_{m}\right)^{2}\right]\right\}^{0.5}$,

- $\mathrm{L}$ is defined as: $\mathrm{L}=\operatorname{erfc}^{-1}(\mathrm{R})$ and:

- $\mathrm{R}=5.5610^{-4} \mathrm{t}_{\mathrm{m}} / \mathrm{H}$

The data $\left(\sigma / t_{m}\right)$, which is the ratio between the standard deviation and the average residence time, is called in statistics the "coefficient of variation" of the distribution $\operatorname{Pdf}(\mathrm{t})$. When one considers very low SI risks, e.g. one SI event over 45,000 hours, $\mathrm{L}$ can be taken in the order of 4.5.

Inequality (5) is interesting as it can be used in two ways:

\section{A) Adapting the design of PrZ in function of the fuel:}

An equivalent form of inequality (5) is:

$$
\sigma / t_{m}<\sqrt{\exp \left\{2\left[\mathrm{~L}-\sqrt{\mathrm{L}^{2}-\ln \left(\mathrm{AID} / \mathrm{t}_{m}\right.}\right]^{2}\right\}-1}
$$

The corresponding curve $\left(\sigma / t_{m}\right)=\mathrm{f}\left(\mathrm{AID} / \mathrm{t}_{\mathrm{m}}\right)$ is drawn in figure 11. In order to have less than one SI in e.g. 45,000 operation hours (about 5 years), one must stay in the region located below this curve which imposes an upper limit for the value of $\sigma$, the standard deviation of the residence time.

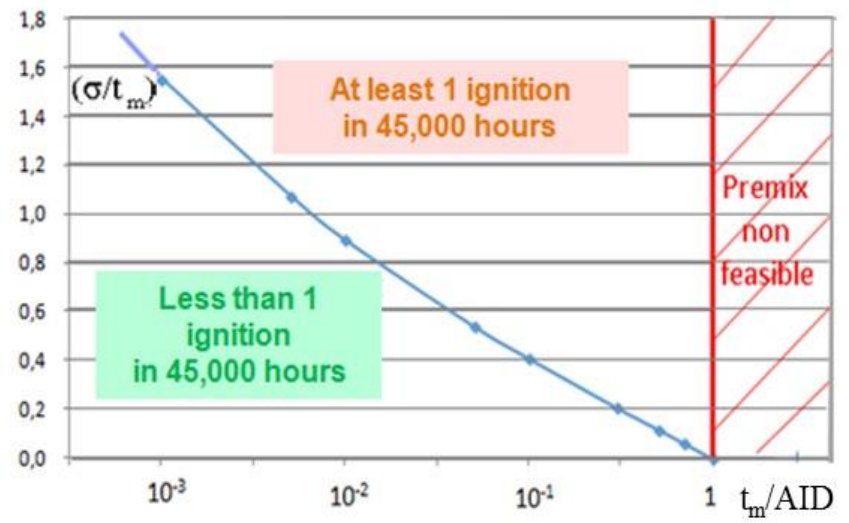

Figure 11: condition to fulfill in order to have a given maximum frequency of SI (here: 1 event/45000 hours).

B) Given a design of the premix zone, evaluate the acceptability of a candidate fuel:

An alternate, equivalent form of equation (5) is:

AID $/ \mathrm{t}_{\mathrm{m}}>\left[1+\left(\sigma / \mathrm{t}_{\mathrm{m}}\right)^{2}\right]^{0.5} \exp \left\{1.41 \mathrm{~L} \times \ln \left[1+\left(\sigma / \mathrm{t}_{\mathrm{m}}\right)^{2}\right]^{0.5}\right\}$

Figure 12 that illustrates this condition shows the minimum $\left(\mathrm{AID} / \mathrm{t}_{\mathrm{m}}\right)$ ratio that is required from a candidate fuel in order to have an SI risk smaller than the specified value (here again: 1 over $45,000 \mathrm{hrs}$ ). For instance, if the average of the residence time in the $\operatorname{PrZ}$ is $2 \mathrm{~ms}$ and its standard deviation does not exceed $0.2 \mathrm{~ms}\left(\sigma / \mathrm{t}_{\mathrm{m}}=0,1\right)$, then one finds a minimum $\left(\mathrm{AID} / \mathrm{t}_{\mathrm{m}}\right)$ ratio of 1.9 , hence AID could be theoretically as low as $3.8 \mathrm{~ms}$.

These simple considerations can be applied to the particular case of the premixing of natural gas fuels containing some amounts of heavier hydrocarbons. This can be illustrated with three fuels studied in the previous section, the AID's of which 
can be calculated from the corresponding correlations drawn from table $2\left(\mathrm{~T}_{\mathrm{PrZ}}=823^{\circ} \mathrm{C} ; \mathrm{P}_{\mathrm{PrZ}}=25\right.$ bar, $\left.\varphi_{\mathrm{PrZ}}=0,7\right)$ :

- $\mathrm{B} 1\left(100 \% \mathrm{CH}_{4}\right): \mathrm{AID}=1.25 \mathrm{~s}$

- $\mathrm{B} 2\left(93 \% \mathrm{CH}_{4}-7 \% \mathrm{C}_{3} \mathrm{H}_{8}\right): \mathrm{AID}=0.47 \mathrm{~s}$

- $\mathrm{B} 3\left(95 \% \mathrm{CH}_{4}-5 \% \mathrm{C}_{4} \mathrm{H}_{10}\right): \mathrm{AID}=0.14 \mathrm{~s}$

Considering an average residence time of $60 \mathrm{~ms}$ and a standard deviation $\sigma$ of $18 \mathrm{~ms}$ with thus $\left(\sigma / \mathrm{t}_{\mathrm{m}}\right)=0.3$, one sees, after placing the three representative points in figure 12, that: $\mathrm{B} 3$ (rich in $\mathrm{C}_{4}$ ) would trigger at least one spontaneous ignition; pure methane (B1) would not and B2 (rich in $\mathrm{C}_{3}$ ) would lie in a "grey area". This emphasizes again the criticality of $\mathrm{C} 2+$ hydrocarbon components in natural gas fuels.

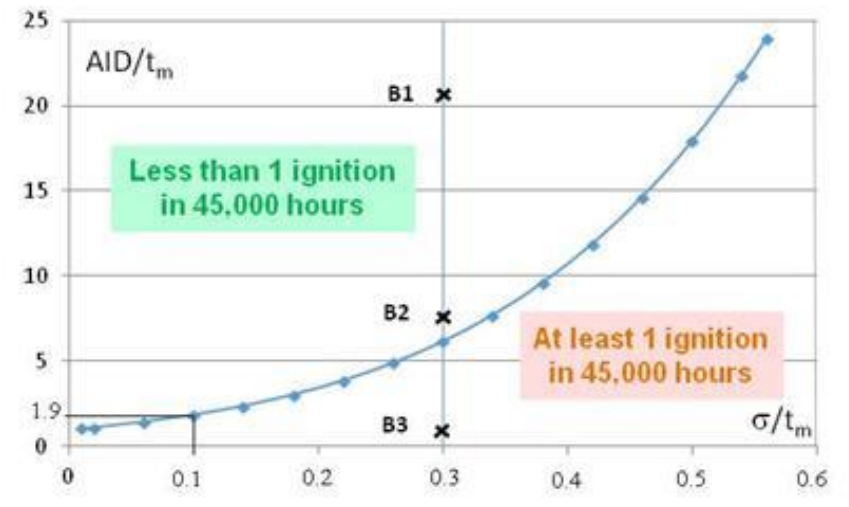

Figure 12: minimum (AID/ $\left.\mathrm{t}_{\mathrm{m}}\right)$ ratio to have a spontaneous ignition risk smaller than a specified value.

One can draw the following general interpretation from this simple approach. To avoid auto ignition in the premixing zone the standard deviation of the residence time distribution in this zone must be reduced by appropriate aerodynamics design. This is achieved in particular by: (i) limiting the volume of the premix zone in order to minimize low speed and local separation zones that increase the residence time; (ii) favoring, on the contrary, intense swirls in the fuel/air mixing process since fast rotational motion greatly improves mixing while not increasing substantially the time of transit. These basic guidelines are actually implemented in all modern combustor designs.

Certainly this oversimplified 0-dimensional approach suffers strong limitations. It ignores factors as: operational transients, possible multimodal distribution of the residence time and non-uniform temperature and fuel/air ratio conditions during the premixing process. Therefore it has essentially an illustrative value of the key role of auto-ignition delays rather than a practical reach.

\section{CONCLUSION}

This work was primarily devoted to the elaboration of a kinetic-based model to quantify the auto-ignition delay (AID) of complex fuels in pressure and temperature conditions different from ambient ones. This work gave the opportunity to emphasize the relevance of this data not only in safety applications but also and especially in the fuel/air premixing processes that are now of common use for the design of DLE systems.

The simple AID correlations obtained, which add to the AIT correlations set out in a previous paper [1], represent potential useful criteria for the evaluation of auto-ignition risks as well as data-driven although not absolute guidelines in the design of premixing devices.

\section{DISCLAIMER}

The information contained in this technical paper represents the best and most current information owned by the authors on the subject and is believed to be correct. However the authors and their respective organizations make no representations or warranties regarding the accuracy and will not be responsible for damages resulting from use or reliance upon this information.

\section{REFERENCES}

[1] Bounaceur R., Glaude P.-A., Sirjean B., Fournet R., Montagne P., Vierling M., Molière M., 2016, « Prediction of Auto-Ignition Temperatures and Delays for Gas Turbine Applications », J. Eng. Gas Turbines Power, 138(2), 021505. [2] Hughes K. J., Turányi T., Clague A. R., Pilling M. J., 2001, «Development and testing of a comprehensive chemical mechanism for the oxidation of methane », Int. J. Chem. Kinet., 33(9), p. 513-538.

[3] Smith G. P., Golden D., Frenklach M., Moriarty N., Eiteneer B., Goldenberg M., Bowman C., Hanson R., Song S., Gardiner W., Lissianski V., Qin Z., « GRI-Mech 3.0 », http://www.me.berkeley.edu/gri_mech/.

[4] de Ferrières S., El Bakali A., Lefort B., Montero M., Pauwels J. F., 2008, «Experimental and numerical investigation of low-pressure laminar premixed synthetic natural gas/O2/N2 and natural gas/H2/O2/N2 flames "), Combustion and Flame, 154(3), p. 601-623.

[5] Konnov A. A., Barnes F. J., Bromly J. H., Zhu J. N., Zhang D., 2005, «The pseudo-catalytic promotion of nitric oxide oxidation by ethane at low temperatures », Combustion and Flame, 141(3), p. 191-199.

[6] Mehl M., Pitz W. J., Westbrook C. K., Curran H. J., 2011, " Kinetic modeling of gasoline surrogate components and mixtures under engine conditions $»$, Proceedings of the Combustion Institute, 33(1), p. 193-200.

[7] Metcalfe W. K., Burke S. M., Ahmed S. S., Curran H. J., 2013, " A Hierarchical and Comparative Kinetic Modeling Study of C1 - C2 Hydrocarbon and Oxygenated Fuels », International Journal of Chemical Kinetics, 45(10), p. 638675.

[8] Tran L.-S., Glaude P.-A., Fournet R., Battin-Leclerc F., 2013, «Experimental and Modeling Study of Premixed Laminar Flames of Ethanol and Methane », Energy \& Fuels, 27(4), p. 2226-2245.

[9] Buda F., Bounaceur R., Warth V., Glaude P. A., Fournet R., Battin-Leclerc F., 2005, «Progress toward a unified detailed kinetic model for the autoignition of alkanes from $\mathrm{C} 4$ to $\mathrm{C} 10$ between 600 and $1200 \mathrm{~K}$ », Combustion and flame, 142(1-2), p. 170-186.

[10] Kee R. J., Rupley F. M., Miller J. A., 1993, « CHEMKIN-II: A FORTRAN Chemical Kinetics Package for the Analysis of Gas-Phase Chemical Kinetics ».

[11] Crossley R. W., Dorko E. A., Scheller K., Burcat A., 1972, «The effect of higher alkanes on the ignition of 
methane-oxygen-argon mixtures in shock waves ", Combustion and Flame, 19(3), p. 373-378.

[12] Petersen E. L., Davidson D. F., Hanson R. K., 1999, " Kinetics modeling of shock-induced ignition in low-dilution $\mathrm{CH}_{4} / \mathrm{O}_{2}$ mixtures at high pressures and intermediate temperatures ", Combustion and Flame, 117(1-2), p. 272290.

[13] de Vries J., Hall J. M., Simmons S. L., Rickard M. J. A., Kalitan D. M., Petersen E. L., 2007, «Ethane ignition and oxidation behind reflected shock waves ", Combustion and Flame, 150(1-2), p. 137-150.

[14] Gallagher S. M., Curran H. J., Metcalfe W. K., Healy D., Simmie J. M., Bourque G., 2008, « A rapid compression machine study of the oxidation of propane in the negative temperature coefficient regime ", Combustion and Flame, 153(1), p. 316-333.

[15] Borisov A. A., Zamansky V. M., Lissianski V., Skachlov G. I., Troshin K. Y., 1988, Prog. Astro. Aeronaut, 114, p. 124.

[16] Minetti R., Ribaucour M., Carlier M., Fittschen C., Sochet L. R., 1994, «Experimental and modeling study of oxidation and autoignition of butane at high pressure ", Combustion and Flame, 96(3), p. 201-211.

[17] Minetti R., Roubaud A., Therssen E., Ribaucour M., Sochet L. R., 1999, «The chemistry of pre-ignition of npentane and 1-pentene », Combustion and Flame, 118(1-2), p. 213-220.

[18] Ogura T., Nagumo Y., Miyoshi A., Koshi M., 2007, "Chemical Kinetic Mechanism for High Temperature Oxidation of Butane Isomers », Energy Fuels, 21(1), p. 130135.

[19] Burcat A., Scheller K., Lifshitz A., 1971, « Shock-tube investigation of comparative ignition delay times for C1-C5 alkanes », Combustion and Flame, 16(1), p. 29-33.

[20] Petersen E. L., Kalitan D. M., Simmons S., Bourque G., Curran H. J., Simmie J. M., 2007, « Methane/propane oxidation at high pressures: Experimental and detailed chemical kinetic modeling », Proceedings of the Combustion Institute, 31(1), p. 447-454.

[21] Lamoureux N., Paillard C.-E., 2003, « Natural gas ignition delay times behind reflected shock waves: Application to modelling and safety », Shock Waves, 13(1), p. 57-68.

[22] Molière M., 2000, « Stationary gas turbines and primary energies: A review of fuel influence on energy and combustion performances », International Journal of Thermal Sciences, 39(2), p. 141-172.

\section{APPENDIX 1: EXPRESSION OF THE PROBABILITY OF SPONTANEOUS IGNITION DUE TO AUTO- IGNITION IN A PREMIXING ZONE}

The Pdf and Cdf functions of the residence time " $t$ " variable write:

$$
\operatorname{Pdf}(\mathrm{t})=\frac{1}{\mathrm{t} \sigma_{\log }^{2} \sqrt{2 \pi}} \exp \left[\frac{-\left(\ln (\mathrm{t})-\mathrm{t}_{m, \log }\right)^{2}}{2 \sigma_{\log }}\right]
$$

$$
\operatorname{Cdf}(\mathrm{t})=\frac{1}{2} \operatorname{erf}\left[\frac{\ln (\mathrm{t})-\mathrm{t}_{m, \log }}{\sqrt{2} \sigma_{\log }}\right]
$$

where $t_{m, \log }$ and $\sigma_{\log }$ are respectively the average and standard deviation of the random variable "ln(t)". The average and standard deviation of the random variable " $t$ ", that are noted $t_{\mathrm{m}}$ and $\sigma$ respectively and are expressed in seconds, are correlated to $t_{m, \log }$ and $\sigma_{\log }$ by the equations:

$$
\begin{aligned}
& t_{\mathrm{m}, \log }=\ln \left(\mathrm{t}_{\mathrm{m}}\right)-1 / 2 \sigma_{\log }^{2} \\
& \sigma_{\text {log }}=\sqrt{\ln \left[1+\left(\sigma / \mathrm{t}_{\mathrm{m}}\right)^{2}\right]}
\end{aligned}
$$

The probability of spontaneous ignition occurring "in one shot", i.e. the probability of an SI occurring while a sole group of molecules crosses the PrZ, is represented by [1-Cdf(AID)]

$$
\operatorname{Prob}(\mathrm{SI})=1-\operatorname{Cdf}(\text { AID })=\frac{1}{2} \operatorname{erfc}\left[\frac{\ln A I D-t_{\mathrm{m}, \log }}{\sqrt{2} \sigma_{\log }}\right]
$$

where the "erfc" function is the complementary of the "erf" function: $\operatorname{erfc}(\mathrm{x})=1-\operatorname{erf}(\mathrm{x})$

Using the parameters $t_{\mathrm{m}}$ and $\sigma$, it comes:

$$
\operatorname{Prob}(\mathrm{SI})=\frac{1}{2} \operatorname{erfc}\left[\frac{\ln \left(\frac{\mathrm{AID}}{t_{m}}\right)+1 / 2 \ln \left[1+\left(\sigma / \mathrm{t}_{\mathrm{m}}\right)^{2}\right]}{\sqrt{2 \ln \left[1+\left(\sigma / t_{m}\right)^{2}\right]}}\right]
$$

During a "reference operation period" $\mathbf{H}$ (in hours) the number of molecules groups crossing the PrZ equals 3600* $\mathrm{H} / \mathrm{tm}$; therefore the frequency of spontaneous ignition writes:

$$
\begin{aligned}
\text { Freq(SI) } & =\frac{3600 * \mathrm{H}}{\mathrm{t}_{\mathrm{m}}} \times \operatorname{Prob}(S I) \\
= & 3600 H / \mathrm{t}_{\mathrm{m}} \times \frac{1}{2} \operatorname{erfc}\left[\frac{\ln \left(\frac{\mathrm{AID}}{t_{m}}\right)+1 / 2 \ln \left[1+\left(\sigma / \mathrm{t}_{\mathrm{m}}\right)^{2}\right]}{\sqrt{2 \ln \left[1+\left(\sigma / t_{m}\right)^{2}\right]}}\right]
\end{aligned}
$$

Consequently, if one wishes to have, for instance, less than one spontaneous ignition in $\mathrm{H}$ operation hours $(\mathrm{Fr}(\mathrm{SI})=1)$, then he must satisfy the following equation in which $\sigma$ and $t_{\mathrm{m}}$ are expressed in seconds and $\mathrm{H}$ in hours:

$$
\operatorname{erfc}\left[\frac{\ln \left(\frac{\mathrm{AID}}{t_{m}}\right)+1 / 2 \ln \left[1+\left(\sigma / \mathrm{t}_{\mathrm{m}}\right)^{2}\right]}{\sqrt{2 \ln \left[1+\left(\sigma / t_{m}\right)^{2}\right]}}\right]<R=5.556 \cdot 10^{-4}\left(\frac{\mathrm{t}_{\mathrm{m}}}{H}\right)(10)
$$

The meaning of the "residue" $\mathrm{R}$ is as follows: if the the erfc function reaches the value $R$, then at least one spontaneous ignition will occur over $\mathrm{H}$ operation hours. For very great value of the reference period $H$, the value of $R$ is very low, e.g.: $\mathrm{R}=1.2410^{-11}$ for $\mathrm{H}=45,000$ hours and $\mathrm{t}_{\mathrm{m}}$ in the order of $0.001 \mathrm{~s}$.

The inequality (10) involves quadratic expression in "S":

$$
0.5 S^{2}-1.41 \text { L.S }+\ln \left(\frac{A I D}{t m}\right)>0
$$

where:

$\mathrm{S}$ is defined as: $\mathrm{S}=\left\{\ln \left[1+\left(\sigma / t_{m}\right)^{2}\right]\right\}^{0.5}$

- $\mathrm{L}$, which is defined as: $\mathrm{L}=\operatorname{erfc}^{-1}(\mathrm{R})$, can be extracted from a table of the erfc function or from a numeric approximation of the reverse of the erfe function.

Since $R$ depends on the ratio $\left(t_{m} / H\right)$, L depends on the same but this dependence is loose due to the asymptotic profile of the $\operatorname{erfc}^{-1}(\mathrm{R})$ function when $\mathrm{R}$ becomes very low; therefore a value of $\mathrm{L}$ in the order of e.g. 4.5 can be taken.

The right member of inequality (8) is an explicit function of $\left(\mathrm{AID} / \mathrm{t}_{\mathrm{m}}\right)$ and an implicit one of $\left(\sigma / \mathrm{t}_{\mathrm{m}}\right)$ (through eq. (9)). Therefore $\left(\mathrm{AID} / \mathrm{t}_{\mathrm{m}}\right)$ and $\left(\sigma / \mathrm{t}_{\mathrm{m}}\right)$ are linked by inequality $(8)$. 